\title{
Instagram Naming Phenomena among Adult and Children
}

\author{
Siti Nurul Hamidah ${ }^{1}$
}

${ }^{1}$ University of Indonesia Awardee of LPDP (Indonesia Endowment Fund for Education)

\section{ARTICLE INFO}

Keywords:

instagram; Language

Variation;

Sociolinguistic;

Username.

\begin{abstract}
Creating a username on Instagram is also a unique phenomenon among children and adult and analyzing how children and adult naming their Instagram will be the main focus of this research. Apparently children and adult have a different way of thinking and social interaction circle. Children could not use variation in creating Instagram username yet caused by limited social interaction they have in society however they use a combination of punctuation or numbers as a form of their creativity. Unlike the adult who has many different social circles, their Instagram naming pattern also varies.
\end{abstract}

\section{Introduction}

The era of globalization has had a huge influence on everyday life. The internet is one of the media in communicating and delivering information that is very rapidly developing which makes the world seem unlimited. That advantage is used by humans in all fields. Humans can easily get the latest information about their own country or other countries regarding political, economic, cultural, fashion and other issues. In line with the development of technology, applications for communication other than the short message service (SMS) also developed, such as Line, WhatsApp, Kakao Talk, Telegram and many others. There are also many social media applications popping up starting from Friendster, Facebook, Twitter, Path, Instagram, and so on. This social media application that exists today can be said as a platform that is loved by the public to communicate. On this social media site or application, we can write and share the various information we want to convey and all the activities we do to our social media accounts.

At present, children have been exposed to devices from an early age. They are very easy to adapt to the features of the device and also the various social media applications that exist at the moment, one of 
which is Instagram. Instagram is one of the social media applications where you can share photos or videos for free and is simple to use. Since smartphones are typically used by an individual, images captured with these devices 'relate directly with that one user's everyday point of view and experience' (Chesher, 2012: 106). In addition, we can click "love" or comments to all the photos or videos that we like.

The ease of using the Instagram application makes this application attractive to the people of Indonesia. According to Indonesia's Facebook Country Director, Sri Widowati, at a press conference on July 26, 2017, presented the data on the statistic of Facebook and Instagram users. From these data, it is known that Indonesia is one of the largest Instagram communities in the Asia Pacific, as many as 45 million Indonesians actively using Instagram. This data increased significantly from 22 million users from Indonesia in early 2016. In making this Instagram account, users are required to write their account name. Naming on Instagram is the topic of this research problem, how children and adult using their creativity when creating username.

\subsection{Research Question}

Problems that will be discussed in the study are: How are children and adults naming their Instagram account? What language variations are there in creating Instagram's username among children and adults?.

\subsection{Research purposes}

The purpose of this research is to describe how children and adults name their Instagram accounts. Describe the distinction language variation and pattern between children and adults that appear when creating the Instagram username

\subsection{Research methods}

The data in this study were taken using a survey consisting of 13 question. Respondents was divided into two categories by age. Age classification according to the Indonesia Ministry of Health (2013: 8) is:

1. 1st grade elementary school/ equivalent: 7 years

2. Elementary school age/ equivalent: 7 - 12 years old

3. Youth/ young adult: $<15$ years old

4. Productive Age Population: 15 - 64 Years

In this study respondents taken from elementary school age with the age range of 8 - 12 years and productive age with age above 15 years as an adult category. Data collection is carried out for two weeks, starting from November 30 to December 15, 2017, and distributed randomly. From this study, 138 data were collected with 42 respondents from children respondents and 96 respondents from the age range above 
15 years. The author makes the equal distribution of respondents quota so that the data taken is only as many as 84 respondents with a distribution of 42-42 among children and adults and each with an age quota of 16 male respondents and 26 female respondents.

\section{Theoritical Framework}

\subsection{Sociolinguistics}

Sociolinguistics describes the relationship that occurs between the variety of languages that exist and social factors in society. The difference in language on the face of the earth is influenced by the diversity of existing communities. Every language user must be different from other language users, each of which has different social factors. As said Holmes (2008: 1) Sociolinguists study the relationship between language and society and they are interseted in explaining why we speak differently in different social contexts, and they are concerned with identifying the social functios of language and the ways it is used to convey social meaning. This variety of languages that exist on this earth cannot be separated from humans as speakers of languages. Every individual user of language is different from other individuals who are influenced by differences in social factors. This language diversity arises from the language user who chooses a language that is tailored to whom he speaks, where, when and in what social environment, so that one language can be different if spoken by different people. The object of the study of sociolinguistics is no longer discussing social phenomena that occur in society but linguistic phenomena found in society. According to Wardhaugh (2010) social factors that also influence an individual's identity are "Consequently, many factors affect it: race, ethnicity, gender, religion, occupation, physical location, social class, kinship, leisure activities, etc. Identity is created in dealing with such factors and in dealing with members of group for whom these factors are among their identifying characteristics." In Linguistic context Holmes (2008:6) also explained because of these similarities of their social factor, "sociolinguists use the term variety (or sometimes code ) to refer to any set of linguistic forms which patterns according to social factors. Variety is a sociolinguistic term referring to language in context. A variety is a set of linguistic forms used under specific social circumstances, i.e., with a distinctive social distribution. Variety is therefore a broad term which includes different accents, different linguistic styles, different dialects and even different languages which contrast with each other for social reasons."

\subsection{Age}

The social variations in society also influence the emergence of various social groups. The formation of these groups is because individuals in them seek similarities with others, then they form a 
group or community. There are groups based on age, gender, social status, occupation, level of education, place or region and others. In those specific groups, a variety of languages is formed. In this social group, each individual is bound. As a member of a social group, each individual must comply with the rules agreed upon in the group so that the variety of languages contained in the group is also agreed upon. So, in each of the differences in social factors that form a social group, a different language is formed which has its own usage rules. One of the social factor is Age. Age is also one of the most important that cause variations in the language in the community. According to Ammon (2006: 2334) "Age is a core" factor "taken into account in sociolinguistic variations. The age of stratification of linguistic variables (how, on average, one of the most diffuse uses) is to reflect change in one or both two senses: (a) change in the normative speech of the community over time (indicating historical change); (b) change in speech of individuals as they move through life."

Children, adolescents, and adults have different ways of speaking. According to Holmes (2008: 176) "Not only pitch, but vocabulary, pronunciation and grammar can differentiate age groups; Children are increasingly acquiring new vocabulary and control of grammatical constructions." In other words, the more mature children, they will get a new vocabulary. They start to learn a formal language with correct grammar and adults are also expected to use formal standard language because of interactions with the wider community as in the work or education environment.

Differences in age social factors can be reflected in the use of language used by an individual. According to Holmes (2008: 4) "Sociolinguists are also interested in different types of linguistic variation used to reflect social factors. Vocabulary or word choice is one area of linguistic variation. But linguistic variation occurs at other levels of linguistic analysis too: sound, word structure (or morphology), and grammar (or syntax) as well as vocabulary." Language variety based on age also have linguistic characteristic, Holmes (2008:80) said that nativised varieties may express the local aspirations and identities of a wide range of communities, and this is reflected in linguistic characteristics such as stress patterns, vocabulary from local languages, grammatical features, which indicate the influence of local languages, and semantic concepts drawn from the other languages spoken in the communities where they are used. Gross (1998:170) said about linguistic characteristic that might found in the language varieties:

1. Sound and syllabic combinatorics and word play (for example, the "ududefu language" in children and something similar)

2. Particularly preferred inflectional and word formation patterns

3. Also here a special vocabulary (exaggerated words, metaphors, puns, vulgarisms, nicknames)

4. A special body language

One characteristic found in language varitaion is word formation. As mentioned by Gross (1998: 171) 'Particularly preferred inflectional and word formation patterns'. The definition of word formation 
according to Busch (2008: 94) is 'Word formation: the process of forming a new word, which is useful for expanding the vocabulary of a language. That is combined or changed into a morpheme that is different from the others. From Busch's definition, it can be understood that word formation is formed from one word to another so that it forms a new word, which is different from the word formation. According to Volmert (1999: 105), there are three main types of formation the composition, the derivation, the conversion.

A nicknames another characteristic we could find in language variation. Individuals in certain social groups might have nicknames that are only understood by members in that social group. Nickname is a name someone gives to someone else, an object that makes it easier to remember. A nickname usually characterizes a person or object and is confirmed by Dahrendorf (1998: 64) that the nicknames should characterize the persons, but not offend them. Nickname can change if the character of the person changes as Kaplow said (2002: 124) that people would change a nickname if the characteristics of the speaker also change. So there is limitation in using nicknames, only a few people or in certain groups could understand the meaning and the name does not apply to the overall scope of language.

The development of humans on earth makes the language in the world also experience rapid development. Ohoiwutun asserted about language development and change (1997: 16) that production and perception of speech, the language developed slowly, as humanity developed. And there are many particular social reasons for choosing a particular code or variety in this multilingual community including using foreign language as a choice. The use of foreign words is also commonly used as an alternative language. Holmes also mentioned (2008:43-44) lexical borrowing results from: Lack of vocabulary in a language and no obvious word available in the language and borrowing of this kind generally involves single words mainly nouns - and it is motivated by lexical need.

In society, often used abbreviations, especially in written language. The use of abbreviations in the community clearly shows how abbreviations affect language. As Kuegler explained (2006: 3) an important part of the written language is the many forms of abbreviations. The number of abbreviation uses according to Gross (1998: 200) should have been counted up to 90,000. Abbreviations are used by the community to make it easier for pronunciation or writing. In cambridge dictionary, abbreviations are also formed by omitting one or more syllables from a word that sometimes called "clipping". Usually, the abbreviation is to abbreviate long sentences or the name of an institution or others. Besides abbreviations, the use of acronyms is also often used by the language user. Cambridge dictionary define acronyms are words which are formed from the first letters of other words. Examples of the use of abbreviations and acronyms in everyday life: ROM, PC, TV, CD, NC, Aids, DJ, Profi. It is no exception in a social group, that individuals use many abbreviations, especially in written language to make them easier to remember. However, not all people understand the terms in these abbreviations or acronym, only members of the social group since they set their own linguistic rules. 


\subsection{Instagram}

Instagram is an free application for photo and video-sharing owned by Facebook, Inc. created by Kevin Systrom and Mike Krieger in 2010, at first available exclusively only on iOS. As a photo and videosharing application Instagram allows users to take photographs, apply digital photographic filters, and upload the image, together with a short caption. Taken from Zappavigna (2016) Instagram describe about their application:

When we were kids we loved playing around with cameras. We loved how different types of old cameras marketed themselves as 'instant' - something we take for granted today. We also felt that the snapshots people were taking were kind of like telegrams in that they got sent over the wire to others - so we figured why not combine the two? (Instagram, 2014)

In creating Instagram account, users are given the freedom in choosing their social media account however the limitation of the characters are only up to 30. Boyd (2010) said that social networking services have a number of characteristic attributes: persistence (capture and archiving of content), replicability (duplication of content), scalability (broad visibility of content) and searchability (access to content via search). Searchability is one of consideration when someone in creating username on the contrary you can also add periods, numbers, underscores or abbreviations to help you come up with a username that's not already in use (Instagram, 2018). According to Joyner (2015) your username plays a crucial role for your account to be easily discovered. your followers will use this to mention you are trying to make it memorable yet cool. It can be concluded that each individual has their own identity which is influenced by social factors including age. Geertz (1973: 363), naming is a crucial aspect of converting “anybodies" into "somebodies."

"When the registration window appears it will prompt you to enter a username and a password. Here you can be very creative because it can be anything you like, with your password there are no limits.

It can be an alias, your real name, something you like or a combination of all. As a Senior be careful to make it something that is identifiable so that family and friends can readily find you. For instance,

it could be your last and first name combined in uppercase." (Tranton, 2015)

This unique individual identity that could be distinguish when they create an account on Instagram social media. So, creating username in Instagram that is up to the account owner can also show linguistic variations based on their age. A discourse of self is 'activated' via the Instagram user's profile, featuring a profile picture and username (Zappavigna, 2016).

\section{Analysis}

The author takes data that is disseminated through surveys that are disseminated and carried out on November 30 - December 14, 2017. The data obtained, 84 respondents were classified based on 
occupational categories, age and gender. There were 42 respondents for each category of adults and children with 16 men and 26 women each. The data shown on Instagram accounts among children and adults, using real names, abbreviations, acronyms, pseudonyms, nickname, vocal language removal, and foreign language. The following is an analysis:

\subsection{Real Name}

Among children and adults, the use of real names got the highest percentage, which is $33 \%$ or 14 respondent in adults category and in children category $74 \%$ or 31 respondent. Using real name in Instagram is because it is easy to find and recognize. However, there are 3 adult respondents who combine their names with numbers and punctuation "_" (underscore) and "." (dot). For examples:

Adults:

$\circ$ Dico Novarido Naldo $\rightarrow$ dico.naldo

○ Satrio Wahyu Harnanto $\rightarrow$ satrio_wahyu_harnanto

○ Sugianto $\rightarrow$ was born June 16, $1994 \rightarrow$ sugianto1694

In addition, there are those who use real names but reverse their first names into last names, here are examples:

○ Intan Satria $\rightarrow$ satriaintan

○ Shelly Rahmania $\rightarrow$ rahmaniashelly

Whereas among 31 children who use real name there are 22 children who combine their real names using the underscore punctuation underscore "_" or dot "." And out of 22 children, only 3 people have a combination of numbers based on their date or month or year of their birthdate. For example:

- Abyan Hudaya $\rightarrow$ date of birth January 24, 2008, $\rightarrow$ abyan_0124

Random numbers:

- Aima Ghina Syakira $\rightarrow$ date of birth July 24, 2008, $\rightarrow$ Aima_ghina_73

- Natasya sonjaya $\rightarrow$ Date of birth 11 May $2006 \rightarrow$ Natasya_4861

From these data, it can be seen that the use of real names among children and adults aims to be easily searchable and recognizable. Although the use of real names occupies the first position but can be seen in the percentage comparison namely $33 \%$ in adults and $74 \%$ children. This means that the adult category has more variations in creating a username. The highest percentage in children category $74 \%$ or as many as 31 of the 42 respondents using real names. Then, 22 children combine their Instagram username using punctuation or numbers. This indicates that children might lack vocabulary however they still express themselves by combining using punctuation or number. 


\subsection{Abbreviation}

The use of abbreviated names is mostly done by adults, as many as $14 \%$ or 6 respondents while children only 1 respondent which is only $2 \%$. The use of abbreviations for naming Instagram children and adults still uses real names. This abbreviation aims to make their Instagram names not too long since Instagram limited its username only up to 30 characters. Here are examples of abbreviation in "clipping" format:

$\circ$ Ani romdayani $\rightarrow$ romday

$\circ$ Fadly Alfiansyah $\rightarrow$ Fadlyalf

$\circ \quad$ Nurina Azzyati $\rightarrow$ nurinazy

$\circ$ Donny Mohammad Ramdhan $\rightarrow$ donny.mora

Here are examples in children category:

- Muhammad Irsyad Athallah $\rightarrow$ Athallah + Irsyad $\rightarrow$ Athallirs

The use of abbreviation in Instagram is so that the name of their Instagram account is not too long. In 'clipping' format respondent keep the beginning of the word and 'clip' the rest of the word.

\subsection{Acronyms}

In adult category the use of acronyms in creating Instagram username is 2 nd highest percentage after using real name which is $21 \%$ or 9 respondents use this format. However in children category only 3 respondents or $7 \%$ use it. Here's an example:

○ Novia Ningsih $\rightarrow$ NoviaN

- Muhammad Irvandi Herlambang $\rightarrow$ mirvandih

○ Novi Sri Wahyuni $\rightarrow$ novi_s _wahyuni

- Regina Dyah Pradani Saraswati $\rightarrow$ rdpsarasw

○ Siti eka soniawati $\rightarrow$ s.ekasoniaw

In children category they combine their username using punctuation or numbers:

- Muhammad Rizieq Naufal $\rightarrow$ date of birth 5 November $2005 \rightarrow$ Mrnaufal0505

- Yukio Nidal Ahmad $\rightarrow$ yukio.n.a

- Bilqis Visya Marwa Salamah $\rightarrow$ Bilqisvisyams_

\subsection{Nickname}

Among adults, nicknames get percentage $12 \%$ or as many as 5 respondents who use nicknames as their Instagram names. The nickname that appears has several patterns, namely by combining the original 
name with a nickname or with a date of birth or idol character or adding random words only for aesthetics. Here are examples:

- Adila Fahmida Saptari $\rightarrow$ her nickname is Mbee $\rightarrow$ adilambee

$\circ$ Adinda Zakiah $\rightarrow$ is called "AZ"; $\mathrm{Z}$ is pronounced /z/ then changes pronunciation to [jet] $\rightarrow$ adindajet

- Dina Sabaruddin $\rightarrow$ often called as Udin, she was born 30 November $\rightarrow$ dinaudin30

- Herlinawati $\rightarrow$ her nickname is Lina + "Lho" is a word when someone want to emphasize something or in this name means you want to suppress that this account is belong to Lina $\rightarrow$ Linalho

$\circ$ Indri Lencia Novelyn $\rightarrow$ nickname chacha combined with her idol figure Iker Cassilas $\rightarrow$ chachacillas

In children category only one respondent or $2 \%$ use their nickname as username:

- Muhammad Aryan Dafa $\rightarrow$ k.c.aryadafa_cmm

Dafa used the name K.C because their entire family used k.c on their Instagram and "cmm" stands for Club Mickey Mouse, a community where Dafa is a member.

\subsection{Pseudonym}

There are only 6 respondents or $14 \%$ in the adult category and 1 respondents or $2 \%$ in children category who use pseudonyms inspired by idol figures. Here's an example:

○ Ancin nursyah $\rightarrow$ Jeon.Mommy

Jeon is the name of Korean singer Jeon Jungkook from BTS one of Korean boyband and Mommy means Mother in English. So, respondent Ancin wanted to identify himself as the mother of Jeon Jungkook.

- Adinda Septiyarani $\rightarrow$ ahralee9718

Inspired by cartoon character from Japanese manga Dr. Slump. The character actually named Arale Norimaki but she change the name like Korean name but still same pronounciation.

○ Dwi harisman $\rightarrow$ Tan_malaka_mahabrata

Tan Malaka is one of Indonesian national hero in fighting for independence

In children category:

- Muhammad Rifky Balweel $\rightarrow$ Kratos_fns

Rifky's respondents used the term Kratos because they loved the game God of War. Kratos is a god of war or often referred to as a god of strength from Greek mythology in the game God of War. 
The use of pseudonyms that are completely different from their real names that is motivated or inspired by idols. Also the reason they are using pseudonym so their Instagram is not easily known by other people beside their close friends or realtives

\subsection{Vocal Letter/ Vowel Removal}

Removing vocal letter in the Instagram has only 2 respondent or 5\% in both category, adult and children catgeory. Here are the data:

- Satwika Pranaya $\rightarrow$ Stwkprny

○ Willy adipratama $\rightarrow$ urqset

Urqsct stand for "Unrequiescat" $\rightarrow$ Un (english) + Requiescat (spain)

$U n$ - is prefix in english for "not" and Requiescat mean rest, so what the respondent mean is restless.

He remove the consonant because he doesn't want other people know his instagram.

In children category:

- Rahma Nur Amallia $\rightarrow$ Rhmnrr_

- $\quad$ Eudora Richy $\rightarrow$ eudora.rchy

The choice of naming method is motivated by reasons of uniqueness, shortness and

\subsection{Foreign Language}

The use of foreign languages in Instagram found in the category of children and adult. In adult category only 2 respondents or 5\% and in children category slightly higher than adult the percentage is $7 \%$ or 3 respondents. Here are the data:

$\circ \quad$ Willy adipratama $\rightarrow$ urqsct (see explanation in 3.6)

$\circ$ Ancin nursyah $\rightarrow$ Jeon.Mommy (see explanation in 3.5)

In children category:

- Amanda Pinesti Istanto $\rightarrow$ spam_amanda.slime_squishy

- Athiyya Zaifa Ahmad $\rightarrow$ Its_athiyya

- Shamimah Isham $\rightarrow$ Shanum.official

The use of foreign languages in naming Instagram is considered unique by the respondents.

\subsection{Ever Changed the Name of Instagram}

Respondent in the category of adults and children, there were 8 respondents from the adult category or $19 \%$ who had changed their Instagram names and 12 respondents or $29 \%$ of the children's categories. The number of children who have changed their Instagram names is because they are quickly bored with 
their Instagram names as well because they want to be shorter, easily recognizable and searchable. Here's an example:

○ Sugianto $\rightarrow$ from Sugi94 to Sugianto1694

In children category:

- Aima Ghina Syakira $\rightarrow$ from Alexandra_peter becomes Aima_ghina_73

- Yukio Nidal Ahmad $\rightarrow$ from yukionidalahmad.yukio10 becomes yukio.n.a

\section{Summary}

In creating a username on Instagram, the data showed that children not using many variations in adding or combining with other vocabulary or abbreviation or other formats. It shows $74 \%$ of children or as many as 31 children use their own real names however they combine their username with birth date or punctuation for examples, underscores and periods. Then, only $7 \%$ or as many as 3 children use the acronym and foreign language. 2 Children or 5\% use vowel removal. The rests are 1 people each or $2 \%$ who use abbreviation, nickname, and pseudonym.

Unlike the children, in the adult category, they are more diverse in naming their Instagram. The use of real names is the highest percentage of $33 \%$ or 14 people. The use of acronym took place in 2 nd highest which is $21 \%$ or as many as 9 respondents. Abbreviation and pseudonym both have 6 respondents in the adult category or the third highest percentage $14 \%$. Then, the adults that use their nickname as their Instagram username is 5 people or $12 \%$. Lastly, in the last position is vowel removal or vocal letter removal, there are only 2 respondents that use this format or $5 \%$

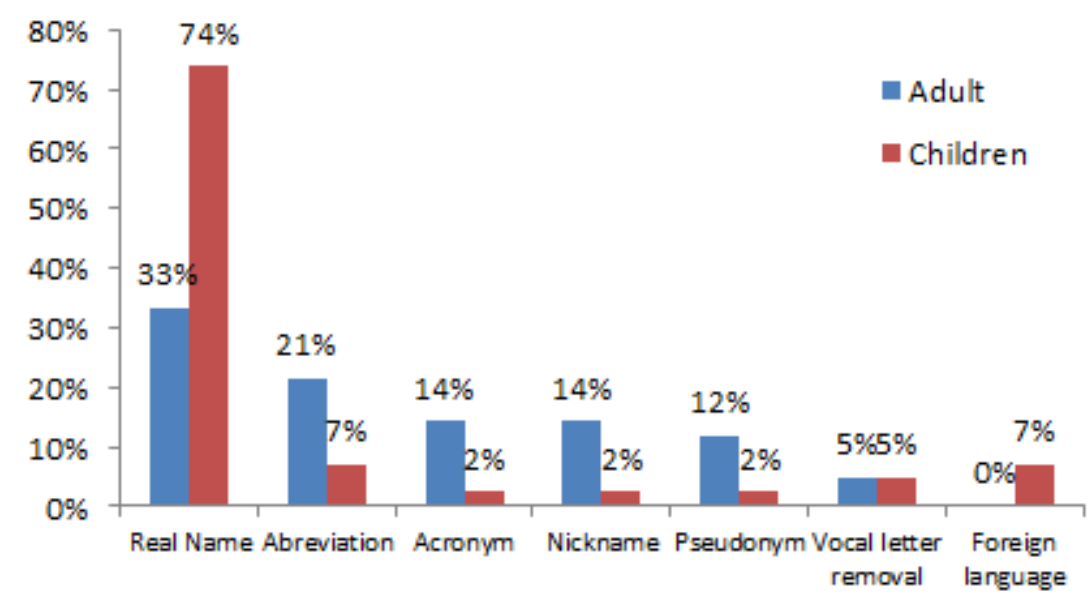

From the data is shown that the children who have a limited social circle or not yet been exposed in worldwide also affect them in acquiring new vocabulary. However, they show their creativity by using 
punctuation or number or a mix between them. There are 32 children or $76 \%$ use their Instagram name with punctuation or number. In the other side, in the adult category, there are many different ways of naming Instagram among adults, their reasons also vary, for example, to make it easy to recognize or easy to find, want to be unique, to make their Instagram name keep simple, also there are some adults that don't want to be found in the social media, so their Instagram name totally different from their real name. Variation in creating a username in Instagram could discover and identify the user. Whereas the variation of Instagram names shows in adults defined that as an adult they have made a lot of contact with other social circles in the community such as in education, hobby, communities, work or professional life, etc. Wider social circle that the adult has, contributes them to acquiring new vocabularies, in result the language they use also varies it shows in how they create their username in Instagram. They are able to come with a lot of ideas, for examples using foreign languages, abbreviation, acronym, pseudonyms, a combination with punctuation, numbers and so on. In the end, how people create their username, cannot be separated from the social factors that the user has, for examples, ages, occupation, and gender. The more the user has a lot of social circles, the more they acquire the new vocabularies and it concludes that language does also develop along with human development.

\section{References}

Ammon, U.: Sociolinguistic: an International Handbook of the Science of Language and Society, Walter de Gruyter, 2006

boyd, D.: Social network sites as networked publics: Affordances, dynamics, and implications. In: Papacharissi, Z. (ed.) A Networked Self: Identity, Community, and Culture on Social Network Sites, Routledge, 39-58, 2010

Busch, A.: Germanitische Linguistik 2. Auflage, Narr Francke Attempto Verlag, 2008

Chaer, A. and Leonie, A.: Sosiolinguistik Perkenalan Awal, PT Rineka Cipta, 2004

Chesher, C.: Between image and information: The iPhone camera in the history of photography. In: Hjorth, L., et al. (eds) Studying Mobile Media: Cultural Technologies, Mobile Communication, and the iPhone. Routledge, 98117,2012

Dahrendorf, M.: Literatur für Einsteiger.: Leseförderung durch Erstleseliteratur, Juventa, 1998

Geertz, C.:The Interpretation of culture, Basic Books, 1973

Gross, H.: Einführung in die germanitische Linguistik, Iudicium Verlag, 1998

Holmes, J.: An Introduction to Sociolinguistics - 4th Edition, Routledge, 2013.

Instagram. Help. Available at: https://help.instagram.com/ (accessed 18 November 2018)

Joyner, J.: Instagram For Beginners: Learn The Basics of Instagram, Get More Likes, Attract New Followers Guide, Speedy Publishing LLC, 2015 
Kaplow, I.: Analytik und Ethik der Namen. Königshausen \& Neumann GmbH, 2002

Kementerian Kesehatan RI. Sekretariat Jenderal.: Profil Kesehatan Indonesia Tahun 2013, Kementerian Kesehatan RI , 2014

Kuegler, S.: Abkürzungen und Akronyme - Verfahren zur automatischen Erkennung von Abkürzungen und Auflösung von mehrdeutigkeiten in biomedizinischen Texten, GRIN Verlag, 2006

Ohoiwutun, P.: Sosiolinguistik: memahami bahasa dalam konteks masyarakat dan kebudayaan, Visipro, 1997

Sumarsono: Sosiolinguistik, Sabda, 2007

Tranton, P.: Instagram for Seniors: An Easy Beginner's Guide, CreateSpace Independent Publishing Platform, 2015

Vivienne, $\mathrm{S}$ and Burgess, J.: The remediation of the personal photograph and the politics of self-representation in digital storytelling. Journal of Material Culture 18, 279-298, 2013

Wardhaugh, R.: An Introduction to Sociolinguistics, Blackwell Publisher, 2010

Zappavigna, M.: Social Media Photography Construing Subjectivity in Instagram Images, Journal of Visual Communication 15, $271-292,2016$

Tempo. https://bisnis.tempo.co/read/894605/45-juta-pengguna-instagram-indonesia-pasar-terbesar-di-asia (accessed 16 desember 2017)

Kompas. http://tekno.kompas.com/read/2017/07/27/11480087/indonesia-pengguna-instagram-terbesar-se-asiapasifik (accessed 16 desember 2017) 